\title{
Trust in Private and Common Property Experiments
}

\author{
Principal Investigators \\ James C. Cox, Georgia State University \\ Elinor Ostrom, Indiana University \\ James M. Walker, Indiana University \\ Collaborators \\ Jamie Castillo, University of Granada \\ Eric Coleman, Indiana University \\ Robert Holahan, Indiana University \\ Michael Schoon, Indiana University \\ Brian Steed, Indiana University
}

\section{(C) 2007 by authors}

\begin{abstract}
We report the results from a series of experiments designed to investigate behavior in two settings that are frequently posited in the policy literature as generating different outcomes: private property and common property. The experimental settings closely parallel earlier experimental studies of the investment or trust game. The primary research question relates to the effect of the initial allocation of property rights on the level of trust that subjects will extend to others with whom they are linked. We find that initial endowments as common property lead to marginally greater cooperation or trust than when the initial endowment is fully owned by the first player as private property. Subjects' decisions are also shown to be correlated with attitudes toward trust and fairness measured in post-experiment questionnaires.
\end{abstract}

\section{Working draft - not to be quoted without authors' permission}

To be presented at the panel on "Fairness Economics and Political Economy" at the $103^{\text {rd }}$ American Political Science Association Annual Meetings, Chicago, Illinois, August 30-September 2, 2007. An earlier version was presented at the $26^{\text {th }}$ Annual Meeting of the Association for Politics and the Life Sciences, Indiana University, Bloomington, October 25-26, 2006. Research support from the National Science Foundation (Grant SES 0083511) and the Workshop in Political Theory and Policy Analysis at Indiana University is gratefully acknowledged. 


\section{Trust in Private and Common Property Experiments}

\section{Introduction}

Numerous experimental studies involving private property endowments have demonstrated that individuals' decisions, in a variety of situations, reflect complex and diverse motivations beyond simple own-income maximization (see, for examples, Camerer, 2003; Camerer and Fehr, 2006; Ashraf, Bohnet, and Piankov, 2006; Cox, Friedman, and Gjerstad, 2007). A largely unexplored question concerns the implications of such fairness behavior for allocation of common property endowments.

The commonly accepted conclusion, roughly derived from the "tragedy of the commons" (Hardin, 1968), is that allocation is much less efficient when property rights are defined as common property than when they are defined as private property. This frequently accepted presumption is, however, a misleading over-simplification and confuses "open access" with "common property." The realization of many of the possible gains from exchange with private property requires trust and reciprocity since contracts are typically incomplete, just as efficient outcomes with common property also require trust and reciprocity. Field studies have challenged the commonly accepted conclusions related to the "tragedy of the commons" and illustrated the substantial difference in incentives and behavior in open access resources (Berkes, et al., 2006) as contrasted to common-property resources (NRC, 1986; NRC, 2002; Dietz, et al., 2003; Dolsak \& Ostrom, 2003). In both experimental and field research, trust appears to be a core variable explaining why participants in some settings tend to cooperate with others while tending not to cooperate in other settings (Ostrom, 2007; Walker and Ostrom, 2007).

Extensive experimental research findings have been generated showing that subjects in "investment game" experiments (commonly also called "trust game" experiments) achieve relatively high levels of return when they are assigned private property rights to a fund that they can either keep or invest in a potentially advantageous way with a stranger (without the presence of a third-party enforcer of contracts). Recently, we have embarked on an experimental program designed to explore in the simplest possible experimental design, whether a fundamental difference exists in the need for trust in private 
property relationships as contrasted to common property relationships. This new and very simple design complements earlier research on time-independent and time-dependant common-pool resources (Ostrom, Gardner, and Walker, 1994).

We have chosen an extremely simple comparison of two settings - a 2-person Private Property Game and a 2-person Common Property Game — both based on the standard Investment Game (Berg, Dickhaut, and McCabe, 1995). In the standard Investment Game (or Trust Game), the first mover, endowed with a private good, makes a decision that can create a surplus to be shared with a second mover because each $\$ 1$ sent to the second mover by the first mover is tripled by the experimenter. The first mover faces a social dilemma, however, in the sense that the second mover will be given full ownership of the fund and full authority over the distribution of the first mover's investment and the resulting surplus. That is, to create the efficiency-enhancing surplus, the first mover must trust that the second mover is trustworthy and will reciprocate the first mover's trust or derive personal satisfaction from being kind to others (Ashraf, Bohnet, and Piankov, 2006; Cox, 2004; Cox and Deck, 2005).

The 2-person Common Property Game is the inverse of the standard Investment Game-which we will call in this paper, the Private Property Game. It is theoretically isomorphic to the Private Property Game because the feasible payoffs for the participants are identical in the two games. In the 2-person Common Property Game, the initial endowment of wealth (equivalent to the maximum possible tripled amount available to the second mover in the Private Property Game) is assigned jointly to the two players. In this game, the first mover has the option of withdrawing resources from the joint fund, and in the process destroying surplus since every dollar withdrawn reduces the joint fund by $\$ 3$. Similar to the Private Property Game, the first mover faces a social dilemma in the sense that the second mover has full authority over the final distribution of the fund remaining after the first mover makes the withdrawal decision. Once again, to refrain from withdrawing from the joint fund, the first mover must either believe the second mover trustworthy of such trust or gain personal satisfaction from being kind to others - as the first mover must do in order to invest a positive amount in the Private Property Game. 
The traditional Investment Game has been examined experimentally by many scholars. The first study to explore this game was undertaken by Berg, Dickhaut, and McCabe (1995). Using a double-blind protocol, the first mover and second mover are each individually endowed with $\$ 10$. The experimenter triples any amounts that are sent by the first mover to the second mover. The second mover then has a decision as to how to divide the amount received. Figure 1 displays the distribution of decisions of first and second movers from the Berg et al. study. As can be observed, a large proportion of first movers sent funds to the second movers. Only two of the first movers sent $\$ 0$. Half of the second movers returned either $\$ 0$ or $\$ 1$. On average, the second movers returned slightly less than first movers sent to them. Hence, on average, the investments by first movers did not pay off.

The experiment undertaken by Berg et al. has been replicated by a large number of scholars in Bulgaria (Koford, 1998), France and Germany (Willinger et al., 2003), Germany (Jacobsen and Sadrieh, 1966), Sweden and Romania (Rothstein and Eek, 2006). Colin Camerer (2003) provides an overview of findings from trust games. In general, one finds that a large proportion of first movers send a substantial portion of their endowments to second movers and many second movers return substantial amounts but, on average, second movers return less than they receive. Findings vary by country and the specific experimental design, but there is more congruence across experiments than disparity. Some experimental designs (for example, Cox, 2004; Cox and Deck, 2005) implement control treatments that discriminate between distinct motives for sending positive amounts (such as altruism or trust) and distinct motives for returning positive amounts (such as altruism or reciprocity). Methodological issues concerning such discriminations have recently been explored (see, for example, Cox, Sadiraj, and Sadiraj, in press). As discussed above, the focus of this study is to expand the set of property rights environments in which the Trust Game is played. In particular, our focus is on the extent to which decisions by first movers and second movers are affected by whether endowments are assigned as private property or common property. In addition, we provide results from both quantitative and qualitative analyses that help understand the rationale behind subjects' decisions. 


\section{Experimental Design and Procedures}

This study incorporates two basic decision settings: (1) 2-person Private Property Game and (2) 2-person Common Property Game. Below, we summarize important details related to each decision setting, as well as the procedures implemented in the laboratory.

\section{A. Decision Settings}

The 2-person Private Property Game examined in this study follows closely that of several earlier studies (in particular, see Berg, Dickhaut, and McCabe, 1995; Cox, 2004, Cox and Deck 2005). Similar to these studies, both subjects begin with a starting balance of 10 tokens, each token having a starting value of \$1. However, the setting examined here differs from the earlier studies in that the second mover has the option of returning all or part of their own initial endowment to the first mover in addition to the option of returning tripled amounts sent by the first mover. Parallel to these earlier studies, the decision protocol applies double-blind procedures.

Subjects are randomly paired as "Type X" and "Type Y" subjects. Each person of Type X decides whether or not to send any of his/her tokens to the paired person of Type Y. Each token that a Type X person sends reduces the value of his/her token fund by $\$ 1$ but increases the value of the tokens of the paired Type Y person by \$3. After the Type X person in a pair makes his/her decision, the Type Y person in that pair makes his/her decision. The Type Y person's decision is to divide the value of the tokens he/she holds between his/her self and the paired person of Type X. That is, the Type Y person decides how much of the fund to keep for his/her self and how much to send back to the Type X person. Appendix A contains the instructions for the 2-person Private Property Game.

The 2-person Common Property Game follows a very similar procedure to the 2-person Private Property Game, except that each pair of decision makers is given a starting balance of 40 tokens in their joint decision fund. The 40 tokens have a starting value of $\$ 1$ each, for a total value of the joint decision fund of \$40. Each person of Type X decides whether or not to withdraw tokens (up to 10 tokens) from the joint decision fund. Each token that a Type X person withdraws has a value to that person of $\$ 1$. Each token 
withdrawn reduces the value of the joint decision fund by $\$ 3$. After the Type X person in a pair makes his/her decision, the Type Y person in that pair makes his/her decision. The Type Y person's decision is to divide between his/her self and the paired person of Type $\mathrm{X}$ the value of the joint decision fund after the Type $\mathrm{X}$ person's withdrawal decision. That is, the Type Y person decides how much of the remaining value of the fund to keep for his/her self and how much to leave for the Type X person.

\section{B. Procedures}

The experiments were conducted in the Interdisciplinary Experimental Laboratory at Indiana University-Bloomington. Subjects were recruited from a database of volunteers. ${ }^{1}$ Due to space limitations in the laboratory, the design called for 12 to 18 subjects per experimental session, with additional subjects recruited as alternates in the case that some subjects did not arrive at the scheduled time. The experiments followed the "double-blind" procedures summarized below.

All sessions began with subjects seated in a large room, where they were instructed not to talk with each other. The experimenter then reviewed, on an overhead projector, the instructions for the decision setting, as well as the procedures to be followed. ${ }^{2}$ Subjects were ensured that there would be complete privacy in terms of personal decisions and earnings. As explained to the subjects, this was accomplished by a procedure in which individuals collected their earnings, contained in a sealed envelope, from a numbered mailbox for which only they had the key. Their privacy was guaranteed because neither their name nor their student ID number appeared on any form that recorded their decisions. The only identifying mark on the decision forms was an identification number known only to the individual. Subjects collected their payoffs with privacy using a key that opened a mailbox located in an adjacent room.

\footnotetext{
${ }^{1}$ A representative from the lab visited various large introductory classes (psychology, geography, and economics) to ask students to enlist in the database if they were interested in participating in experiments. A wide variety of majors are represented in these large introductory classes.

${ }^{2}$ For further experimental control, in all sessions the experimental protocol and instructions were reviewed with the participants by a single experimenter, Walker.
} 
After reviewing the instructions and procedures with the subjects, the experimenter had each participant draw a sealed envelope from a box. The envelope contained a piece of paper marked with the participant's Type (X or Y). All Type X decision makers remained in the room to make their decisions. All Type Y decision makers moved to an adjacent room to make their decisions. Then an experimenter walked through the Type X room carrying a box containing envelopes. Each Type X person took one of the envelopes. Each envelope contained a mailbox key with a private identifying number and a decision form with the same identifying number. Each Type X person then wrote his/her decision on the decision form and placed the form back inside the envelope. Type $\mathrm{X}$ persons were then given a questionnaire to complete in private.

After all Type X decisions were made, an experimenter took the box containing the envelopes with the decisions of the Type $\mathrm{X}$ persons to an adjacent room and added the decision of the Type $\mathrm{X}$ person to the decision form for the Type Y person with whom he/she had been randomly paired. The experimenter then placed the decision form for the Type Y person and a mailbox key with an identifying number in each envelope. An experimenter then walked through the Type Y room carrying the box containing the envelopes. Each Type Y person took one of the envelopes from the box. Each Type Y person then wrote his/her decision on the decision form and put the form back inside the envelope.

After all Type Y decisions were made, an experimenter took the envelopes to an adjacent room. The decisions marked on the Type Y decision forms determined the earnings for each Type X/ Type Y pairing. While waiting for the distribution of payoffs, Type Y persons were given a questionnaire to complete in private. The experimenters placed the payoffs of each person in a sealed envelope marked with the identifying number of that person. The envelope was then placed in that person's mailbox. Each envelope also included a $\$ 5$ show-up payment. After being informed by an experimenter that it was time to receive their payoffs, Type $\mathrm{X}$ persons put their completed questionnaires in an envelope and went to the mailbox room to retrieve their payoff envelopes from their mailboxes. As each person left the lab area, he/she signed an acknowledgment that he/she received a cash payoff for the experiment, but not the amount. Type Y persons then followed the same procedure after all Type X persons had left the lab. 


\section{Results}

\section{A. Descriptive Statistics}

The presentation of results begins with summary descriptive statistics for each experimental design. Recall, Type X refers to first movers, subjects making the initial decision. Type Y refers to second movers, subjects who responded to the decisions made by Type X subjects. Figures 2 and 3 present bar graphs and summary statistics for key behavioral measures from each of the two decision settings. Each bar graph displays the decision by an X-Type, the amount sent to a Y-type in the Private Property Game or the amount left in the group fund in the Common Property Game, as well as the corresponding decision by the Y-Type, the amount $\mathrm{Y}$ returned to $\mathrm{X}$. The decisions are sorted from high to low, first by the $\mathrm{X}$ decision and then by the $\mathrm{Y}$ decision.

Observation 1: As with previous studies of the Trust Game (our Private Property Game), there is large variation in decisions by $X$-Types and the responses by $Y$-Types.

As shown in the figures, we observe an average $\mathrm{X}$ decision (amount sent) of $\$ 5.65$ and a corresponding $\mathrm{Y}$ decision (amount returned) of $\$ 6.65$ in the 2-person Private Property Game, and an average $\mathrm{X}$ decision (amount left) of $\$ 6.71$ with a corresponding Y decision (amount returned) of $\$ 8.76$ in the 2-person Common Property Game. Note that Berg et al. (1995) observe an average X decision of \$5.16 and a corresponding Y decision of $\$ 4.66$ in their baseline (nonsocial history) treatment. Cox (2004) reports an average $\mathrm{X}$ decision of $\$ 5.97$ and a corresponding $\mathrm{Y}$ decision of $\$ 4.94$ in his treatment $\mathrm{A}$.

Observation 2: In comparing decisions of X-Types, the 2-person Common Property Game leads to an increase (not statistically significant) in average tokens left, equivalent to tokens sent in the Private Property Games. ${ }^{3}$

Beyond the average decisions, however, there is an interesting distributional difference in the behavior of $\mathrm{X}$-Types in the two game settings. As shown in the figures, in the 2-person Private Property Game, 11 of

\footnotetext{
${ }^{3}$ Comparing tokens sent (left) by Type X players, 2-person Private Property vs. 2-person Common Property $(\mathrm{t}=1.02$, d.f. $=65, \mathrm{p}=.31)$.
} 
34 Type $\mathrm{X}$ subjects sent all 10 tokens. This compares to 16 of 34 Type X subjects who left all 10 tokens in the 2-person Common Property Game. ${ }^{4}$

Clearly, one interpretation of the difference in behavior observed by X-Types in the 2-person Common Property Game is the existence of joint ownership of the starting fund. That is, in the 2-person Private Property Game, the starting balances were assigned separately to each individual. Similar to how one might interpret a form of a common-property regime setting, however, starting balances in the 2person Common Property Game were assigned mutually to the two individuals.

Observation 3: In comparing decisions of Y-Types, in the 2-person games, there is an increase in the average amount returned in the 2-person Common Property Game, corresponding to the increase in the average amount left by $X$-Types.

Observation 4: The ordering across decision settings for total earnings by Type X subjects is 2-person Private Property < 2-person Common Property. ${ }^{5}$

Finally, one obvious question concerns the a priori "optimal” investment by Type X subjects, given expected responses by Type Y subjects. For both decision settings, Figure 4 plots the average earnings by Type X subjects, contingent on the amount kept, the amount sent to Type Y subjects, and the amount returned by Type Y subjects.

Observation 5: There is no clear evidence of an a priori optimal decision by Type X subjects.

Pooling the data further lends additional support to this conclusion. For X-Types sending or leaving 0 to 5 tokens, average earnings equal \$11.24. For X-Types sending or leaving 6 to 10 tokens, average earnings equal $\$ 11.79$.

\section{B. Model Comparisons across Investment Settings}

In this section, we examine the decisions by Y-Types (\$ Y-Returned) as a linear function of the decisions of corresponding X-Types (X-Decision). All estimates are derived using GLS procedures with

\footnotetext{
${ }^{4}$ Both Kolmogorov-Smirnov and Wilcoxian rank sum distribution tests are not significant ( $p=.26$ and .23 , respectively).

${ }^{5}$ Comparing total earnings by Type X players, 2-person Private Property vs. 2-person Common Property ( $\mathrm{t}=0.81$, d.f. $=65, \mathrm{p}=.42$ ).
} 
robust standard errors. Because of the clustering of data at the end points (in particular 10 tokens), as a robustness check, we also present data from a Tobit analysis.

Model 1: $($ YY-Returned $)=\alpha+\beta(\mathrm{X}$-Decision $)+\mathrm{e}_{\mathrm{i}}$

Table 1 presents the model estimates for each of the decision settings.

Observation 6: Consistent with the summary observations drawn from the descriptive statistics, the magnitude of the coefficient on the variable " $X$-Decision" which measures the marginal dollars returned by $Y$ for each token (\$3) sent by $X$, can be ordered as: 2-Person Private Property < 2-Person Common Property.

Observation 7: Although the linear models do a reasonable job of capturing individual decisions, in all settings there is considerable variation in response by Y-Types unaccounted for by controlling for the $X$-Type decision.

\section{Behind the X\&Y Decisions: Motives and Norms}

The analysis above focuses explicitly on the quantitative measures of subject choices in the two games settings. In this section, using evidence drawn from post-experiment questionnaires, we turn to an analysis of both quantitative and qualitative measures for providing evidence of subjects' motivations and/or norms of behavior.

\section{Model Estimates with Demographics and Attitudes}

We begin first with a reexamination of the decisions made by Type $\mathrm{X}$ decision makers and Type Y decision makers. In particular, the post-questionnaire provides information on two demographic variables of interest: (1) age of the decision maker and (2) gender of the decision maker. In addition, the questionnaire provides qualitative data on each subject's attitude toward trust in others, helpfulness of others, and fairness of others. ${ }^{6}$ Each question allows the responder the opportunity for a negative, a

\footnotetext{
${ }^{6}$ Appendix B contains the post-experiment questionnaires that were used for the 2-person Private Property Game. The questionnaire used for the 2-person Common Property Game is modified only with regard to the alternative framing for the X-type decision maker. Note that because of the game design, first movers, Type X, would not know the results of their decisions at the time they completed the questionnaire. However, second movers, the Type Y subjects, would have completed the questionnaire after observing the decision by the Type $\mathrm{X}$ subject and making their own decision.
} 
positive, and a "don't know" response (coded as a null response in the statistical analysis reported in Table 2). ${ }^{7}$

1. Generally speaking, would you say that most people can be trusted or that you can't be too careful dealing with people?

Can't be too careful, Most people can be trusted, Don't know

2. Would you say that most of the time people try to be helpful or that they are mostly just looking out for themselves?

Just look out for themselves, Try to be helpful, Don't know

3. Do you think that most people would take advantage of you if they got a chance or would they try to be fair?

Most people would take advantage, They would try to be fair, Don't know

After further reflection, we decided that the question related to "helpfulness" was not appropriate for our analysis. Statistical analyses supported this conclusion. The results we report below are robust as to whether the helpfulness questions are eliminated or not.

Based on the survey responses, the first two columns of results in Table 2 (OLS and Tobit) provide model estimates for decisions made by Type $\mathrm{X}$ subjects, as a function of the following independent variables:

2-P Common Property: dummy=1 if decision is from the 2-person Common Property setting;

Age: chronological age of decision maker;

Gender: dummy=1 if male;

Trust Dummy Variables: DumTrust-pos $=1$ if response was positive, DumTrust-null=1, if response was null (“don't know”);

Fairness Dummy Variables: DumFair-pos $=1$ if response was positive, DumFair-null=1, if response was null (“don’t know”).

\footnotetext{
${ }^{7}$ An analysis of the correlation in responses to the three questions by subjects revealed statistical correlations in the range of .20 to .40 for Type $\mathrm{X}$ and $\mathrm{Y}$ subjects.
} 
Thus, the coefficients reported in Table 2 should be interpreted as shifts away from a base condition where the decision maker was in the 2-person Private Property setting, was female, and gave a negative response to each of the two attitudinal variables. ${ }^{8}$

Several interesting observations emerge from the analysis of Type X subjects. In particular, although not statistically significant, there is a positive effect of age and being male. Further, the response to the survey question regarding trust is highly significant and in the expected direction. The fairness variable associated with a positive response is also positive and significant. Thus, those who responded that most people could be trusted sent (left) more tokens than those who disagreed with this statement. Similarly, those who responded that most people would try to be fair also sent (left) more tokens than those who responded that most people would take advantage of them.

Table 2 also reports model estimates for a similar analysis of the Type Y subjects, where the dependent variable is "amount returned" and there is one additional independent variable, "amount sent" by the Type $\mathrm{X}$ decision maker. Parallel to the results reported in Table 1, the amount sent (left) by the Type $\mathrm{X}$ decision maker had a significant affect on the amount returned by the Type $\mathrm{Y}$ decision maker. Interestingly, there is also a highly statistically significant gender effect. Controlling for the amount sent by Type X subjects, Type Y males returned less. The qualitative variables for a positive response are of the expected sign and are statistically significant. However, the null responses for the trust and fairness questions are not statistically significant. In fact, the coefficient for "DumTrust-null" shows a negative relationship with amount returned.

The observation that the "attitudinal" variables appear to be somewhat more closely associated with Type $\mathrm{X}$ decisions than with Type $\mathrm{Y}$ decisions raises an interesting methodological point. As noted, because of the game design, first movers, X-Types, would not know the results of their decisions at the time they completed the questionnaire. However, second movers, the Y-Types, completed the

\footnotetext{
${ }^{8}$ Recall, in the 2-person Common Property Game, the Type X decision maker chooses how many tokens to leave in the group fund. To make this decision comparable to the Type X decision in the 2-person Investment Game, this choice is recoded as (10 minus Tokens Left).
} 
questionnaire after observing the decision by the Type X subject with whom they were matched, and making their own decision.

\section{Selective Comments from the Questionnaires}

Beyond the statistical analysis, the responses to the questionnaires offer useful insights into how subjects perceive the 2-person Private Property and Common Property Games, and to what extent their decisions in the experiment reflect these attitudes. Below, we offer comments from subjects that we found to be particularly insightful (grammatical and spelling errors are part of original subject statements).

Responses: 2-Person Private Property Game

\section{Type X}

"There was not a good enough chance of making my money back if I sent it to the Y person. The risk was not worth it." Player sent 0 .

"If I were a Type Y, I would keep all of the money and Type X would get screwed. This guaranteed me money." Player sent 0.

"The opportunity for more money. Basically I'm trusting the Type Y person splits the money. That way, I'll get a higher pay-off. However, I don't completely trust they'll be fair, so I kept some money for myself." Player sent 7 tokens $(\$ 21)$.

"I wanted to maximize the amount of money that could come back to me. I realize I may not get any back, but you can't get it back if you don't give it up. And it's just ten bucks." Player sent 10 tokens $(\$ 30)$.

\section{Type Y}

"Basically, I was greedy, but I thought since the person X trusted all of their money with me, they deserved some kind of a kick back.” Player Y sent back \$15, after player X sent 10 tokens $(\$ 30)$.

“Why would I give up \$31 when I could keep it?” Player Y sent back \$0, after player X sent 7 tokens $(\$ 21)$.

"I feel bad but I don't know the person and I am a poor college student. But since there was no facing the person I was partnered with they will never know I am the asshole who screwed them." Player Y sent back $\$ 0$, after player X sent 10 tokens $(\$ 30)$.

"Since they were willing to take the risk and optimize both out joint profit, I felt inclined to split it." Player Y sent back \$20, after player X sent 10 tokens $(\$ 30)$. 
"If Type X gave no money to type $\mathrm{Y}$, that person obviously needs the money more than I can say that I need it; therefore, they can have mine also." Player Y sent back \$20, after player X sent 0 tokens $(\$ 0)$.

\section{Responses: 2-Person Common Property Game}

\section{Type X}

"It was my own test. I wanted to see if I left $\$ 40$ in the pot, the other person would take it all or divide it equally. Because I believe human nature is inherently selfish, I'll probably make nothing, but I wanted to trust for once." Player took 0 tokens, leaving the value of the pool at $\$ 40$.

"I assumed that there is no chance of getting all \$40, so I assumed the max was \$20. If I withdrew all the tokens and got $\$ 10$, I assumed Y would take all $\$ 10$. I was risking money to double my money." Player took 0 tokens, leaving the value of the pool at $\$ 40$.

"Risk=Reward...by accepting a possible loss of 10 dollars, I have gained the possibility to gain 20 dollars. Since worst case scenario is I make 5 dollars, I decided it was a reasonable risk." Player took 0 tokens, leaving the value of the pool at $\$ 40$.

"I wanted the best possible outcome for the both of us. I didn't want to be selfish and thought if given the chance hopefully the person I am paired up with is fair." Player took 0 tokens, leaving the value of the pool at $\$ 40$.

"The other person (type Y) would probably withdraw everything for themselves." Player took 10 tokens, leaving the value of the pool at $\$ 10$.

"I did not want to withdraw lower than that and risk the Y person taking all the money and myself get only $\$ 5$." Player took 10 tokens, leaving the value of the pool at $\$ 10$.

\section{Type $\mathbf{Y}$}

"That bastard/bastardette took as much as he/she could, why can't I? Plus, we both get $\$ 15$ anyway." Player Y sent back $\$ 0$, after player X took 10 tokens, and brought the value of the pool to $\$ 10$.

"I'm a little greedy I guess. The X person doesn't know who did what so I figured there was no problem being selfish and taking as much as I could." Player Y sent back $\$ 0$, after player X took 5 tokens, and brought the value of the pool to $\$ 25$.

"They were fair so I wanted to be fair." Player Y sent back \$0, after player X took 5 tokens, and brought the value of the pool to $\$ 25$. Player Y sent back \$20, after player X took 0 tokens, and left the value of the pool at $\$ 40$.

"If the Type X person was smart, he would of withdrawn none of the tokens and allowed me to split the account evenly. He did not trust me to do so; I decided not to let him have an even amount." Player Y sent back \$3, after player X took 5 tokens, and left the value of the pool at $\$ 25$.

"Why would I give them money I can have?” Player Y sent back \$0, after player X took 6 tokens, and brought the value of the pool to $\$ 22$. 


\section{Comments and Conclusions}

This study broadens the growing literature on decision making in the experimental game commonly referred to as the "Trust Game" or the "Investment Game." The primary research question relates to whether there are clear behavioral differences between Private Property and Common Property experiments that can be attributed to players' sense of ownership and/or equitable distribution of gains from trust and cooperation. In particular, we examine to what extent behavior is dependent upon how property rights in endowments are assigned to the subjects. The primary motivation behind the experimental design is drawn from the literature on common-property regimes, where subjects are faced with a social dilemma of how best to manage a commonly owned resource.

In the standard Investment Game, the first mover, endowed with a private good, makes an allocation decision that creates a surplus to be shared with a second mover. The first mover faces a social dilemma, however, in the sense that the second mover has full private ownership and authority over the distribution of the investment and the resulting surplus. The 2-person Common Property Game parallels the standard Investment Game — what we are calling above the Private Property Game - except that in the 2-person Common Property Game, the initial endowment of wealth (equivalent to the maximum possible tripled amount available to the second mover in the Private Property Game) is assigned jointly to the two players. Now the first mover has the option of withdrawing resources from their joint endowment, and in the process destroying surplus since every dollar withdrawn reduces the joint fund by $\$ 3$. Similar to the standard Investment Game, the first mover faces a social dilemma in the sense that the second mover has full authority over the final distribution of the investment and any resulting surplus.

In summary, we find that endowments that are induced as common property lead to marginally greater cooperation or trust. Relative to the Private Property Game, in the Common Property Game, subjects are more likely to leave the full joint fund untouched (parallel to sending the full endowment in the first Game). Second movers respond by returning, marginally, more to the first movers. However, in 
terms of overall earnings, the Common Property games leads to only a 5 percent increase over the Private Property Game.

Subjects' decisions are shown to be correlated with attitudes toward trust and fairness measured in post-experiment questionnaires. Both a quantitative analysis related to response to the questionnaire and excerpts from subjects' open-ended comments suggest that many of the subjects see both of these games as primarily related to trust and reciprocity. However, there clearly exists a tension for first movers as to how much trust to extend and, for some second movers, a clear motivation to reap the benefits of trust. Finally, an interesting set of results related to gender emerge. Although not statistically significant, the results suggest that males invest slightly more than females as first movers. However, as second movers, males return statistically less to first movers.

The overall results are intriguing since many scholars presume that owners of common property will be less trusting and cooperative than owners of private property. Future experiments will be conducted to analyze the robustness of this study through increased replication of the decision environment and moving to Private Property and Common Property Games with more than two players. 
Figure 1: 2-Person Investment Game Decisions from Berg, Dickhaut, and McCabe (1995)

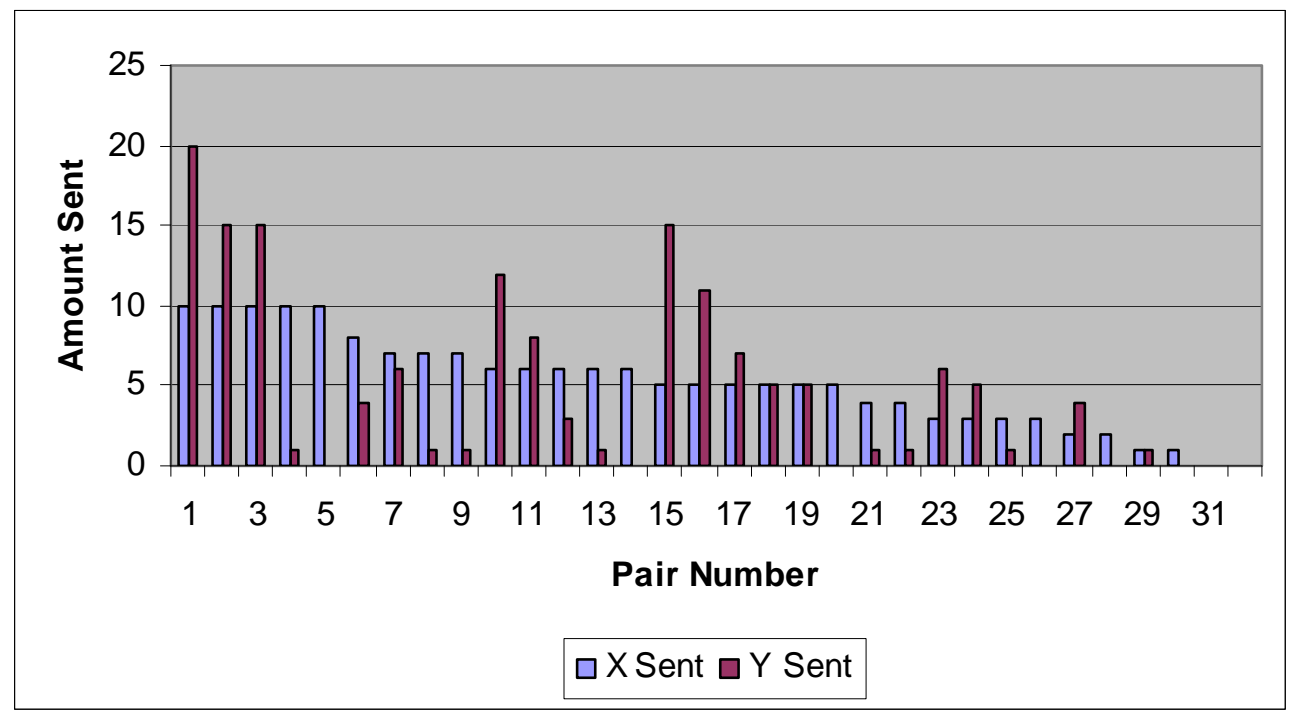

\begin{tabular}{|l|c|c|c|c|}
\hline \multicolumn{5}{|c|}{$\begin{array}{c}\text { Berg, Dickhaut, and McCabe } \\
\text { Type X \& Type Y- N=32 }\end{array}$} \\
\hline & Mean & $\begin{array}{c}\text { Standard } \\
\text { Deviation }\end{array}$ & Minimum & Maximum \\
\hline Tokens X Sent & 5.16 & 2.94 & 0 & 10 \\
\hline \$ Y Returned & 4.66 & 5.55 & 0 & 20 \\
\hline \$ X Earned & $\$ 9.50$ & 4.89 & 0 & 20 \\
\hline \$ Y Earned & $\$ 20.82$ & 7.87 & 10 & 40 \\
\hline
\end{tabular}


Figure 2: 2-Person Private Property Game Decisions and Descriptive Statistics

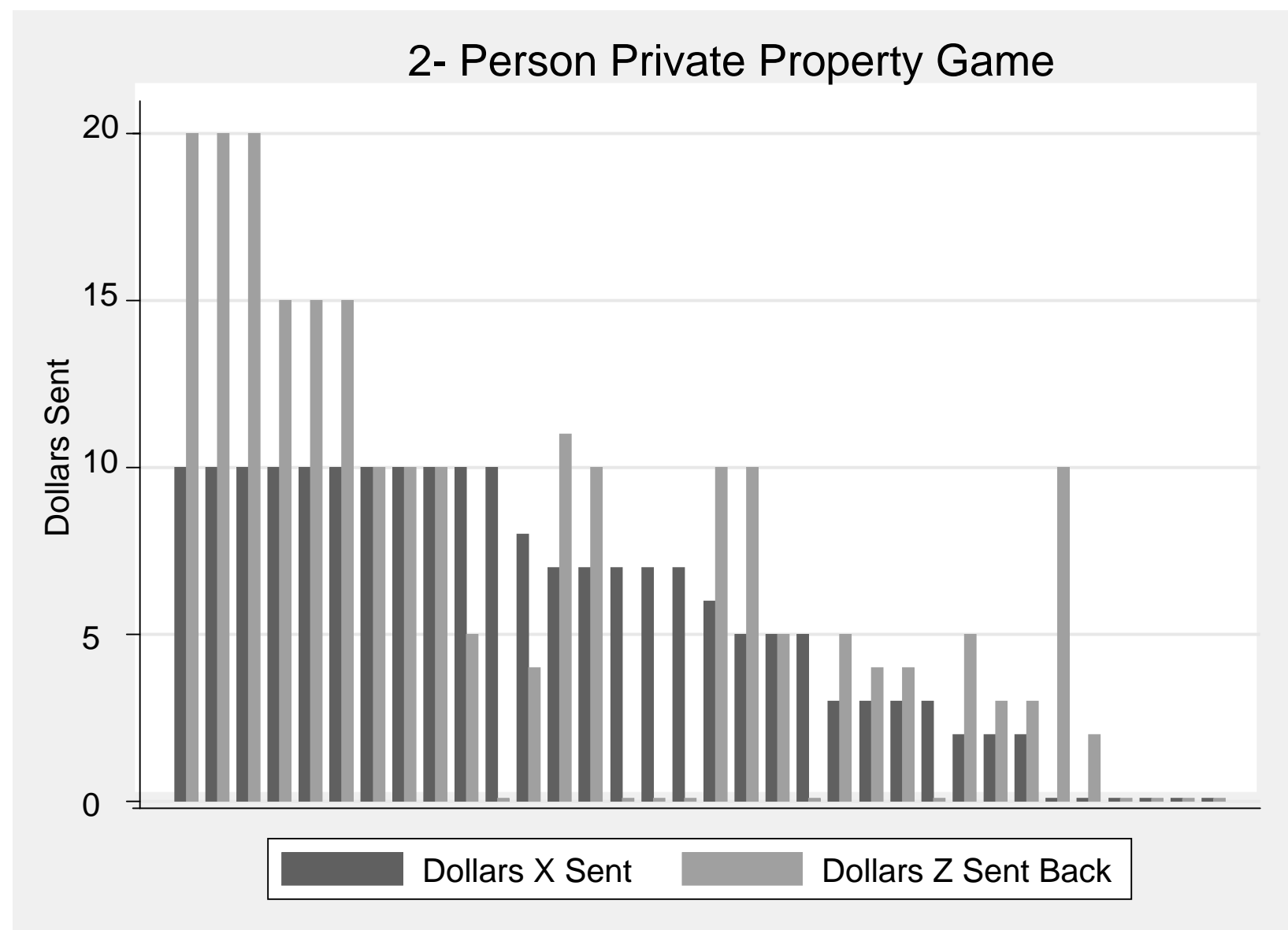

\begin{tabular}{|l|c|c|c|c|}
\hline \multicolumn{5}{|c|}{$\begin{array}{c}\text { 2-Person Private Property Game } \\
\text { Type X \& Type Y- N=34 }\end{array}$} \\
\hline & Mean & $\begin{array}{c}\text { Standard } \\
\text { Deviation }\end{array}$ & Minimum & Maximum \\
\hline Tokens X Sent & 5.65 & 3.83 & 0 & 10 \\
\hline \$ Y Returned & 6.65 & 6.43 & 0 & 20 \\
\hline \$ X Earned & 11.00 & 5.08 & 0 & 20 \\
\hline \$ Y Earned & 20.29 & 9.09 & 0 & 40 \\
\hline
\end{tabular}

Note: As shown on the far right side of the figure, there were 4 observations where Type $\mathrm{X}$ sent $\$ 0$ and Type $\mathrm{Y}$ returned $\$ 0$. 


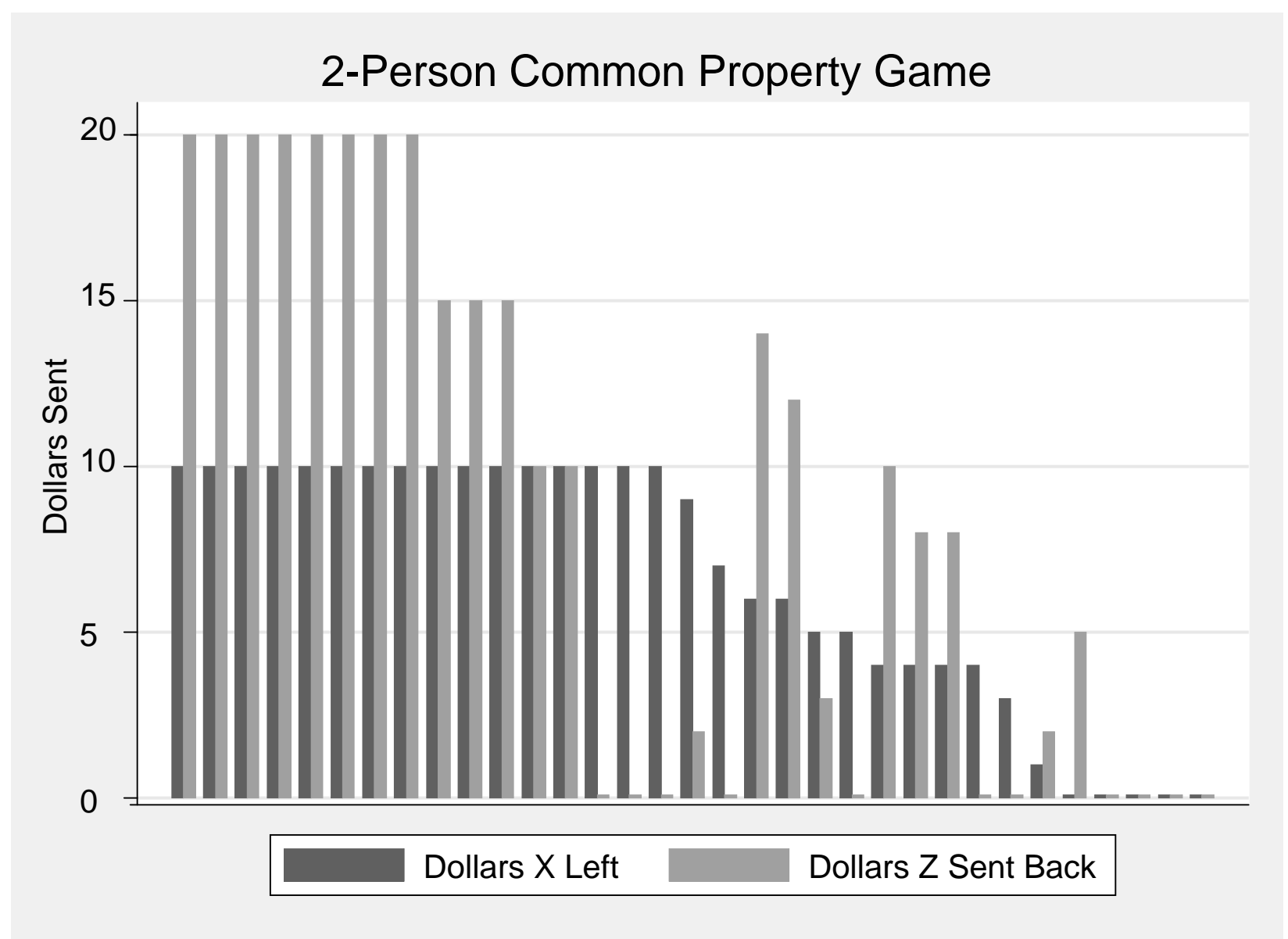

\begin{tabular}{|l|c|c|c|c|}
\hline \multicolumn{5}{|c|}{$\begin{array}{c}\text { 2-Person Common Property Game } \\
\text { Type X \& Type Y- N=33 }\end{array}$} \\
\hline & Mean & $\begin{array}{c}\text { Standard } \\
\text { Deviation }\end{array}$ & Minimum & Maximum \\
\hline Tokens X Left & 6.71 & 3.88 & 0 & 10 \\
\hline \$ Y Returned & 8.76 & 8.20 & 0 & 20 \\
\hline \$ X Earned & 12.12 & 6.60 & 0 & 20 \\
\hline \$ Y Earned & 20.85 & 9.76 & 5 & 40 \\
\hline
\end{tabular}

The analysis presented in Figure 3 excludes one observation that was omitted because of clear confusion on the part of one subject. The X-type player left all tokens, leaving the Y-type player with $\$ 40$ to allocate. The Y-type player allocated all $\$ 40$ to the X-type player. On the questionnaire, he/she commented: "Logic, if both people left all the money, then they would get more in the end. $\$ 10$ was the most you could receive if you took all the tokens, $\$ 20$ if you split the joint fund."

Note: As shown on the far right side of the figure, there were 4 observations where Type $\mathrm{X}$ sent $\$ 0$ and Type $\mathrm{Y}$ returned $\$ 0$. 
Figure 4: Earnings of $X$ Types in Both Experiments

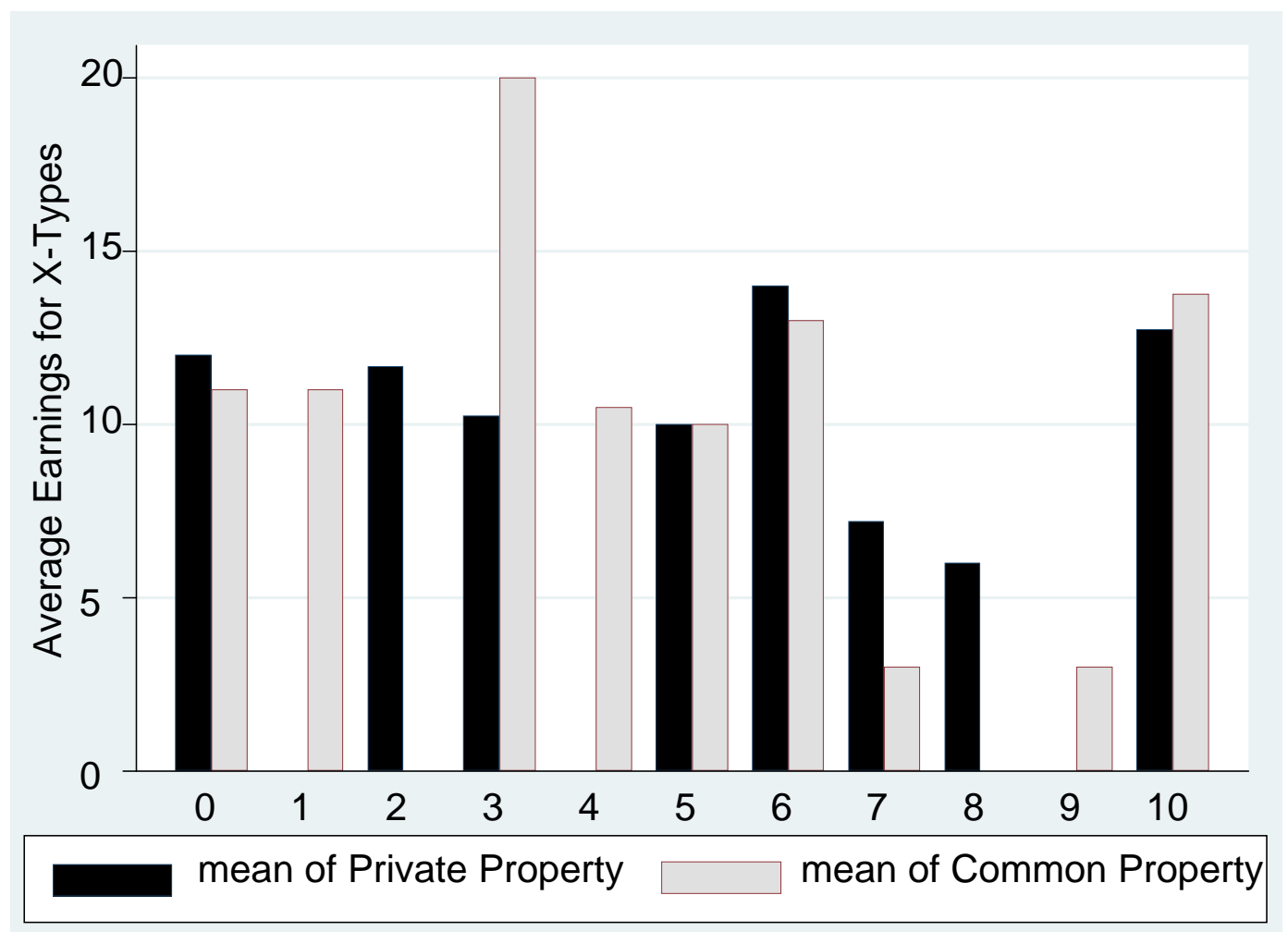


Table 1: Linear Model Estimates Across Experiments*

\begin{tabular}{|c|c|c|c|c|}
\hline & $\begin{array}{c}\text { 2-Person } \\
\text { Private } \\
\text { Property } \\
\text { OLS } \\
\end{array}$ & $\begin{array}{c}\text { 2-Person } \\
\text { Private } \\
\text { Property } \\
\text { Tobit } \\
\end{array}$ & $\begin{array}{c}\text { 2-Person } \\
\text { Common } \\
\text { Property } \\
\text { OLS }\end{array}$ & $\begin{array}{c}\text { 2-Person } \\
\text { Common } \\
\text { Property } \\
\text { Tobit } \\
\end{array}$ \\
\hline Constant & 0.82 & -1.95 & 0.11 & -5.54 \\
\hline & $(p=0.472)$ & $(p=0.398)$ & $(p=0.923)$ & $(p=0.141)$ \\
\hline X-Sent & 1.03 & 1.29 & & \\
\hline & $(p=0.000)$ & $(p=0.000)$ & & \\
\hline X-Left & & & 1.31 & 1.83 \\
\hline & & & $(p=0.000)$ & $(p=0.000)$ \\
\hline R-squared & 0.36 & 0.07 & 0.39 & 0.08 \\
\hline $\mathrm{N}$ & 34 & 34 & 33 & 33 \\
\hline
\end{tabular}

*OLS results use robust standard errors. The Type $\mathrm{Y}-$ Tobit model uses left censoring at 0 . 
Table 2: Linear Model Estimates—-Type X\&Y Decisions*

\begin{tabular}{|c|c|c|c|c|}
\hline & $\begin{array}{l}\text { Type X } \\
\text { Decisions }\end{array}$ & $\begin{array}{l}\text { Type X } \\
\text { Decisions }\end{array}$ & $\begin{array}{l}\text { Type Y } \\
\text { Decisions }\end{array}$ & $\begin{array}{l}\text { Type Y } \\
\text { Decisions }\end{array}$ \\
\hline $\begin{array}{l}\text { Dependent } \\
\text { Variable }\end{array}$ & Amount Sent & Amount Sent & $\begin{array}{l}\text { Amount } \\
\text { Returned }\end{array}$ & $\begin{array}{l}\text { Amount } \\
\text { Returned }\end{array}$ \\
\hline & OLS & Tobit & OLS & Tobit \\
\hline Constant & $-5.08(p=.267)$ & $-17.07(p=.175)$ & $-2.71(p=.664)$ & $5.18(\mathrm{p}=.642)$ \\
\hline 2P-Common Prop & $1.24(\mathrm{p}=.147)$ & $2.57(p=.165)$ & $1.22(p=.365)$ & $0.67(p=.723)$ \\
\hline Age & $0.40(\mathrm{p}=.079)$ & $0.91(\mathrm{p}=.138)$ & $0.17(\mathrm{p}=.556)$ & $-0.39(p=.471)$ \\
\hline Gender & $1.10(\mathrm{p}=.177)$ & $1.61(p=.396)$ & $-3.09(\mathrm{p}=.037)$ & $-4.87(p=.012)$ \\
\hline DumTrust-pos & $2.91(\mathrm{p}=.003)$ & $6.96(p=.007)$ & $3.41(p=.046)$ & $4.17(p=.044)$ \\
\hline DumTrust-null & $2.87(\mathrm{p}=.040)$ & $6.54(\mathrm{p}=.052)$ & $-2.53(p=.244)$ & $-4.50(p=.161)$ \\
\hline DumFair-pos & $2.06(\mathrm{p}=.023)$ & $3.56(p=.098)$ & $2.90(p=.079)$ & $5.28(\mathrm{p}=.016)$ \\
\hline DumFair-null & $1.21(\mathrm{p}=.370)$ & $3.01(p=.269)$ & $2.02(\mathrm{p}=.228)$ & $3.44(p=.126)$ \\
\hline $\begin{array}{l}\text { Type X: Amount } \\
\text { Sent }\end{array}$ & Not Applicable & Not Applicable & $0.961(p=.000)$ & $1.224(\mathrm{p}=.000)$ \\
\hline R-squared & 0.313 & 0.089 & 0.522 & 0.131 \\
\hline $\mathrm{N}$ & 68 & 68 & 67 & 67 \\
\hline
\end{tabular}

* OLS results use robust standard errors. The Type $\mathrm{X}$ - Tobit model uses upper and lower censoring. The Type Y-Tobit model uses left censoring at zero and robust standard errors. 


\section{Appendix A: 2-Person Private Property Game}

\section{Two Types}

The participants in today's experiment will be randomly divided into two types, referred to as Type X and Type Y.

\section{Random Pairing and Anonymity}

Each person of Type $\mathrm{X}$ will be randomly paired with a person of Type $\mathrm{Y}$. No one will learn the identity of the person with whom he/she is paired. As discussed below, Type X persons will make their decisions anonymously in one room, and Type Y persons in another room.

\section{Starting Balances}

Each person in a pair of decision-makers will be given a starting token fund of 10 tokens. The 10 tokens have a starting value of one dollar each, for a total value of $\$ 10$.

\section{Complete Privacy}

This experiment is structured so that no one, including the experimenters or the other participants, will ever know the personal decision or money earnings of anyone in the experiment. This is accomplished by a procedure in which you collect your earnings, contained in a sealed envelope, from a numbered mailbox that only you have the key for. Your privacy is guaranteed because neither your name nor your student ID number will appear on any form that records your decisions in this experiment. The only identifying mark on the decision forms will be an identification number known only to you. You will be able to collect your money payoffs with privacy by using a key, which opens a mailbox located in a room adjacent to this room. The key and mailbox will be labeled with the same number as your decision-reporting forms. But you will be the only person who knows your personal number.

\section{The Type X Decision Task}

Each person of Type $\mathrm{X}$ will decide whether or not to send any of his/her tokens to the paired person of Type Y. Each token that a Type $\mathrm{X}$ person sends reduces the value of his/her token fund by $\$ 1$ but increases the value of the token fund of the paired Type Y person by $\$ 3$. A Type X person cannot send more than his initial 10 token starting balance. Four examples illustrate how the values of the tokens that may be sent by Type $\mathrm{X}$ are related to the value of the Type $\mathrm{Y}$ token fund.

- If the Type $\mathrm{X}$ person sends 0 tokens, that reduces the value of his/her fund by $\$ 0$ and adds $\$ 0$ to the value of the fund held by the paired Type Y person.

- If the Type $X$ person sends 1 token, that reduces the value of his/her fund by $\$ 1$ and adds $\$ 3$ to the value of the fund held by the paired Type Y person.

- If the Type $\mathrm{X}$ person sends 5 tokens, that reduces the value of his/her fund by $\$ 5$ and adds $\$ 15$ to the value of the fund held by the paired Type Y person.

- If the Type $\mathrm{X}$ person sends 10 tokens, that reduces the value of his/her fund by $\$ 10$ and adds $\$ 30$ to the value of the fund held by the paired Type Y person.

\section{The Type Y Decision Task}

After the Type $\mathrm{X}$ person in a pair makes his/her decision, the Type $\mathrm{Y}$ person in that pair makes his/her decision. The Type Y person's decision is to divide the value of the token fund he/she holds between his/her self and the paired person of Type X. That is, the Type Y person decides how much of the fund to keep for his/her self and how much to send back to the Type $\mathrm{X}$ person. 


\section{Experiment Procedures - We will review all procedures before we begin.}

1. Each participant will draw a sealed envelope from the box. That envelope will contain a piece of paper marked with the participant's Type (X or Y).

2. All Type $\mathrm{X}$ decision makers will remain in this room to make their decisions. All Type $\mathrm{Y}$ decision makers will move to an adjacent room to make their decisions.

3. An experimenter will walk through the Type X room carrying a box containing large manila envelopes. Each Type X person can take any one of the envelopes from the box. Each envelope contains a mailbox key with a private identifying number and a decision form with the same identifying number written on the Type X Key Number line on the form.

4. Each Type $X$ person writes his/her decision on the decision form and then puts the form back inside the manila envelope. The key is NOT put back in the envelope. Each Type X person puts his/her manila envelope containing the decision form back in the box on the table at the front of the room and picks up a questionnaire to fill out.

5. An experimenter takes the box containing the manila envelopes with the decisions of the Type $\mathrm{X}$ persons to an adjacent room. The experimenter adds the decision of the Type $\mathrm{X}$ person on the decision form for the Type $\mathrm{Y}$ person with whom he/she has been randomly paired. The experimenter places the decision form for the Type Y person and a mailbox key with an identifying number in each envelope. These are the mailbox keys for the Type Y persons. The experimenter also writes the identifying number from the key onto the Type Y Key Number line on the form.

6. An experimenter will walk through the Type $\mathrm{Y}$ room carrying the box containing the manila envelopes. Each Type $\mathrm{Y}$ person can take any one of the envelopes from the box. Each envelope contains a mailbox key with a private identifying number and a decision form marked with a Type X person's decision.

7. Each Type $\mathrm{Y}$ person writes his/her decision on the decision form and then puts the form back inside the manila envelope. The key is NOT put back in the envelope. Each Type Y person puts his/her manila envelope containing the decision form back in the box on the table at the front of the room and picks up a questionnaire to fill out.

8. An experimenter takes the box containing the manila envelopes to an adjacent room and removes the decision forms from the envelopes. The decisions marked on the forms determine how much each person gets paid.

9. The experimenters place the experiment payoffs of each person in a sealed envelope marked with the identifying number of that person. The envelope will be placed in that person's mailbox. Each envelope will also include the $\$ 5$ show up fee.

10. Before leaving the experiment, each participant will note their involvement in this experiment on the computer in front of them. This is done by logging on the computer using instructions that will be given at that time.

11. After being informed by an experimenter that it is time to receive their payoffs, Type X person will put their completed questionnaires in an envelope that will be provided and then place the questionnaires in a box at the front of their room. Type $\mathrm{X}$ person will then go to the mailbox room and retrieve their payoff envelopes from their mailboxes, and leave the key in the mailbox. As each person leaves the lab area, he/she will be asked to sign an acknowledgment that he/she received a cash payoff for the experiment.

Type Y persons will follow the same procedure after all Type X persons have left the lab. 


\section{2-Person Common Property Game Instructions}

\section{No Talking Allowed}

Now that the experiment has begun, we ask that you do not talk. If you have a question after we finish reading the instructions, please raise your hand and the experimenter will approach you and answer your question in private.

\section{Two Types}

The participants in today's experiment will be randomly divided into two types, referred to as Type X and Type Y.

\section{Random Pairing and Anonymity}

Each person of Type $\mathrm{X}$ will be randomly paired with a person of Type $\mathrm{Y}$. No one will learn the identity of the person with whom he/she is paired. As discussed below, Type X persons will make their decisions anonymously in one room, and Type Y persons in another room.

\section{Starting Balances}

Each pair of decision-makers will be given a starting balance of 40 tokens in their joint decision fund. The 40 tokens have a starting value of one dollar each, for a total value of the joint decision fund of $\$ 40$.

\section{Complete Privacy}

This experiment is structured so that no one, including the experimenters or the other participants, will ever know the personal decision or money earnings of anyone in the experiment. This is accomplished by a procedure in which you collect your earnings, contained in a sealed envelope, from a numbered mailbox that only you have the key for. Your privacy is guaranteed because neither your name nor your student ID number will appear on any form that records your decisions in this experiment. The only identifying mark on the decision forms will be an identification number known only to you. You will be able to collect your money payoffs with privacy by using a key, which opens a mailbox located in a room adjacent to this room. The key and mailbox will be labeled with the same number as your decision-reporting forms. But you will be the only person who knows your personal number.

\section{The Type X Decision Task}

Each person in Type $\mathrm{X}$ will decide whether or not to withdraw tokens from the joint decision fund. Each token that a Type X person withdraws has a value to that person of $\$ 1$. Each token withdrawn reduces the value of the joint decision fund by $\$ 3$. A Type $X$ person cannot withdraw more than 10 tokens. Four examples illustrate how the values of the tokens remaining in the decision fund are related to the values of the tokens that may be withdrawn:

- If the Type $\mathrm{X}$ person removes 0 tokens, that adds $\$ 0$ to his/her earnings and does not change the value of the joint decision fund.

- If the Type $\mathrm{X}$ person removes 1 token, that adds $\$ 1$ to his/her earnings and reduces the value of the joint decision fund by $\$ 3$.

- If the Type $X$ person removes 5 tokens, that adds $\$ 5$ to his/her earnings and reduces the value of the joint decision fund by $\$ 15$.

- If the Type $\mathrm{X}$ person removes 10 tokens, that adds $\$ 10$ to his/her earnings and reduces the value of the joint decision fund by $\$ 30$.

\section{The Type Y Decision Task}

After the Type X person in a pair makes his/her decision, the Type $\mathrm{Y}$ person in that pair makes his/her decision. The Type $\mathrm{Y}$ person's decision is to divide between his/her self and the paired person of Type $\mathrm{X}$ the value of the joint decision fund after the Type X person's withdrawal decision. That is, the Type Y person decides how much of the remaining value of the fund to keep for his/her self and how much to leave for the Type $\mathrm{X}$ person. 


\section{Appendix B: Post-Experiment Questionnaires}

\section{Type X Subjects}

Thank you very much for participating in our decision experiment. We would like to ask you a few questions about your experience in this experiment and about you. What is Your Key Number?

\section{Questions about the experiment:}

1. Is this the first decision experiment in which you have participated? Yes ___ No

2. If your answer to \#1 is "No", approximately how many other experiments have you been in?

3. Were the experiment instructions clear? Yes_ No

4. Did you have any questions you wanted to ask us? If yes, please briefly write them in the space provided

5. Did you send all or some of your tokens to the Type Y person with whom you were paired? Yes No

If yes, how many tokens did you send?

What were your reasons for making the decision that you made?

\section{More general questions:}

1. Generally speaking, would you say that most people can be trusted or that you can't be too careful dealing with people?

Most people can be trusted Can't be too careful Don't know

2. Would you say that most of the time people try to be helpful or that they are mostly just looking out for themselves?

Try to be helpful Just look out for themselves Don't know

3. Do you think that most people would take advantage of you if they got a chance or would they try to be fair?

Most people would take advantage __ They would try to be fair Don't know

\section{Information about you:}

What year are you in school? Freshman What is your intended or declared major?

What is your age?

What is your gender? Female

Junior Senior Sophomore

Male




\title{
Type Y Subjects
}

Thank you very much for participating in our decision experiment. We would like to ask you a few questions about your experience in this experiment and about you. What is Your Key Number?

\section{Questions about the experiment:}

1. Is this the first decision experiment in which you have participated? Yes No

2. If your answer to \#1 is "No", approximately how many other experiments have you been in?

3. Were the experiment instructions clear? Yes_ No

4. Did you have any questions you wanted to ask us? If yes, please briefly write them in the space provided

5. Did the Type X person with whom you were paired send all or some of their token fund to you? Yes _ No

If yes, how much money from their fund did they send you?

How much did you send to the Type $\mathrm{X}$ person with whom you were paired?

What were your reasons for making the decision that you made?

\section{More general questions:}

1. Generally speaking, would you say that most people can be trusted or that you can't be too careful dealing with people?

Most people can be trusted Can't be too careful Don't know

2. Would you say that most of the time people try to be helpful or that they are mostly just looking out for themselves?

Try to be helpful Just look out for themselves Don't know

3. Do you think that most people would take advantage of you if they got a chance or would they try to be fair?

Most people would take advantage __ They would try to be fair___ Don't know

\section{Information about you:}

What year are you in school? Freshman What is your intended or declared major? What is your age?

What is your gender? Female Junior ___ Senior Male 


\section{References}

Ashraf, Nava, Iris Bohnet, and Nikita Piankov. 2006. "Decomposing Trust and Trustworthiness." Experimental Economics 9(1): 193-208.

Berg, Joyce, John Dickhaut, and Kevin McCabe. 1995. "Trust, Reciprocity, and Social History." Games and Economic Behavior 10: 122-42.

Berkes, Fikret., et al. 2006. "Globalization, Roving Bandits, and Marin Resources.” Science 311: 15571558.

Binmore, K. G. 1998. “The Evolution of Fairness Norms.” Rationality and Society 10(3): 275-301.

Camerer, Colin. 2003. Behavioral Game Theory: Experiments in Strategic Interaction. Princeton, NJ: Princeton University Press.

Camerer, Colin, and Ernst Fehr. 2006. "When Does 'Economic Man’ Dominate Social Behavior.” Science 311: 47-52.

Cox, James C. 2004. "How to Identify Trust and Reciprocity." Games and Economic Behavior 46: 26081.

Cox, James C., and Cary A. Deck. 2005. "On the Nature of Reciprocal Motives." Economic Inquiry 43(3): 623-36.

Cox, James C., Daniel Friedman, and Steven Gjerstad. 2007. “A Tractable Model of Reciprocity and Fairness." Games and Economic Behavior 59(1): 17-45.

Cox, James C., Klarita Sadiraj, and Vjollca Sadiraj. In press. "Implications of Trust, Fear, and Reciprocity for Modeling Economic Behavior.” Experimental Economics.

Dolšak, Nives, and Elinor Ostrom, eds. 2003. The Commons in the New Millennium: Challenges and Adaptations. Cambridge, MA: MIT Press.

Dietz, Thomas, Elinor Ostrom, and Paul Stern. 2003. "The Struggle to Govern the Commons.” Science 302 (December 12): 1907-12.

Fehr, Ernst, and Klauss Schmidt. 1999. “A Theory of Fairness, Competition, and Cooperation.” Quarterly Journal of Economics 114: 817-68.

Hardin, Garrett. 1968. “The Tragedy of the Commons.” Science 162: 1243-48.

Jacobsen, Eva, and Abdolkarim Sadrieh. 1966. "Experimental Proof for the Motivational Importance of Reciprocity.” Working Paper. Bonn: University of Bonn.

Koford, Kenneth. 1998. "Trust and Reciprocity in Bulgaria: A Replication of Berg, Dickhaut and McCabe (1995).” Working Paper. Newark: University of Delaware, Department of Economics.

National Research Council. 1986. Proceedings of the Conference on Common Property Resource Management. Washington, D.C.: National Academy Press. 
National Research Council. 2002. The Drama of the Commons. Committee on the Human Dimensions of Global Change. Elinor Ostrom, Thomas Dietz, Nives Dolšak, Paul Stern, Susan Stonich, and Elke Weber, eds. Washington, DC: National Academy Press.

Ostrom, Elinor. 2007. "To Trust or Not to Trust? That is the Question." Paper to be presented at the symposium on "Games, Groups, God(s), and the Global Good," Princeton University, October 46, 2007.

Ostrom, Elinor, Roy Gardner, and James Walker. 1994. Rules, Games, and Common-Pool Resources. Ann Arbor: University of Michigan Press.

Rothstein, Bo, and Daniel Eek. 2006. "Political Corruption and Social Trust - An Experimental Approach." Presented at American Political Science Association meeting, Philadelphia, August 31-September 3.

Rabin, M. 1993. "Incorporating Fairness into Game Theory and Economics." American Economic Review 83(5): 1281-302.

Walker, James and Elinor Ostrom. 2007. "Trust and Reciprocity as foundations for Cooperation: Individuals, Institutions, and Context." Paper presented at the Capstone Meeting of the RSF Trust Initiative at the Russell Sage Foundation, May 2007. To appear in a volume edited by Karen Cook, Margaret Levi, and Russell Hardin.

Willinger, Marc, Claudia Keser, Christopher Lohmann, and Jean-Claude Usunier. 2003. "A Comparison of Trust and Reciprocity between France and Germany: Experimental Investigation Based on the Investment Game.” Journal of Economic Psychology 24(4): 447-66. 